\title{
FAKTOR-FAKTOR YANG BERHUBUNGAN DENGAN CAKUPAN IMUNISASI DASAR PADA BAYI DI DESA KAJHU KECAMATAN BAITUSSALAM ACEH BESAR TAHUN 2009
}

\author{
Factors Related To Primary Immunization Coverage In Infant In The Village Of Aceh \\ Baitussalam Kajhu District of 2009 \\ Wirda Hayati' ${ }^{1}$ Dewi Marianthi ${ }^{2}$, Nurleli ${ }^{3}$ \\ ${ }^{1,2,3)}$ Program Studi Keperawatan Banda Aceh PolTekKes DepKes RI Nanggroe Aceh Darussalam \\ ${ }^{*}$ ee-mail: wirda_hayati@yahoo.com
}

\begin{abstract}
ABSTRAK
Imunisasi memberikan daya proteksi optimal agar bayi terhindar dari penyakit infeksi bila diberikan sesuai dengan interval yang telah ditentukan, namun jumlah bayi yang mendapat imunisasi dasar lengkap belum sesuai dengan standar cakupan imunisasi yang ditetapkan pemerintah. Penelitian ini bertujuan untuk mengetahui faktor-faktor yang berhubungan dengan cakupan imunisasi dasar pada bayi di Desa Kajhu Kecamatan Baitussalam Aceh Besar. Desain penelitian berupa metoda deskriptif korelatif dengan pendekatan cross sectional dan menggunakan teknik pengumpulan data simple random sampling. Pengumpulan data dilakukan dari tanggal 26 Maret sampai dengan 9 April 2009 terhadap 52 responden ibu yang memiliki anak usia 1 tahun dengan menggunakan kuisioner dan angket. Berdasarkan hasil analisis data secara bivariat menunjukkan terdapat hubungan cakupan imunisasi dengan motivasi ibu ( $\mathrm{p}$ value $=0,003$ ), dan dukungan keluarga ( $\mathrm{p}$ value $=0,000)$, namun tidak terdapat hubungan dengan pendidikan ibu $(\mathrm{p}$ value $=0,115)$ dan konseling ( $\mathrm{p}$ value $=0,402$ ). Diharapkan kepada dinas kesehatan dapat berkoordinasi dengan Puskesmas, memodifikasi teknik penyuluhan, mengefektifkan meja 4 posyandu, menggunakan stake holder sebagai role model, serta selalu mengevaluasi penyuluhan berdasarkan feed back dari masyarakat.
\end{abstract}

Kata kunci: cakupan lima imunisasi dasar pada bayi, pendidikan ibu, motivasi ibu, dukungan keluarga, konseling.

\begin{abstract}
Immunization will be optimal protection to prevent the infection diseases for infant if they get it's with appropriate schedule, but many infants didn't got the basic immunization dissuitable with government program. This study had aims to identify the factors had relationship with the basic immunization for infant coverage in di Desa Kajhu Kecamatan Baitussalam Aceh Besar. Desaign this study was correlative descriptive with cross sectional study, the sample tecnic with simple random sampling. Data collection start at March, 26 until April, 9, 2009 for 52 respondent were the mother of infant (age 12 month) in Desa Kajhu Kecamatan Baitussalam Aceh Besar used questionaire and check list. The result study were bivariate analysis shown that the immunization coverage with mother motivation ( $p$ value $=0,003$ ), family support ( $p$ value $=0,000$ ), but there didn't had relationship between the mother education ( $p$ value $=0,115)$ and counseling ( $p$ value $=0,402$ ). For distric health office must be coordination with the Puskesmas, to modify education strategy to make the community awareness for immunization, effectivity of the $4^{\text {th }}$ table in posyandu, use lay of community or stake holder as role model, and evaluation of education activity based on community feedback.
\end{abstract}

Keys Word: basic immunization coverage for infant, education level of mother, motivation, family support, counseling.

\section{LATAR BELAKANG}

Salah satu cara menghindari penyakit pada bayi yang efektif adalah meningkatkan sistem kekebalan tubuh dengan memberikan obat khusus yang disebut vaksin melalui imunisasi. Imunisasi dapat menghindari berbagai penyakit seperti hepatitis, campak, 
polio, cacar, tetanus, difteri, batuk rejan dan TBC (Irianto \& Waluyo, 2004). Beberapa faktor yang berhubungan dengan kelengkapan lima imunisasi dasar yang wajib meliputi BCG, hepatitis B, DPT, polio dan campak. Menurut penelitian Suminar di Desa Patra Sengon Kecamatan Patrang Kabupaten Jember tahun 2008, didapatkan bahwa faktor tingkat pendidikan dan motivasi ibu, dukungan keluarga serta konseling dari petugas kesehatan merupakan faktor yang berpengaruh terhadap pemberian imunisasi, sehingga menambah cakupan imunisasi.

Standar cakupan imunisasi untuk Indonesia yang telah ditetapkan dan wajib dipenuhi oleh instansi kesehatan termasuk Puskesmas untuk lima imunusiasi dasar yaitu $80,5 \%$ dari jumlah bayi yang menjadi sasaran. Standar yang telah ditetapkan tersebut ditargetkan dapat dicapai pada tahun 2009. Namun kenyataannya secara umum, standar ini belum mampu dipenuhi oleh sebagian besar daerah di Indonesia (DepKes RI, 2007).

Rendahnya cakupan imunisasi dasar tersebut umumnya disebabkan oleh kurangnya pengetahuan mengenai Kejadian Ikutan Pasca Imunisasi (KIPI). KIPI yang dialami bayi setelah imunisasi dapat berupa kesakitan sampai dengan kematian meskipun untuk hal yang disebutkan terakhir sangat jarang terjadi. KIPI yang sering ditemukan setelah pemberian imunisasi meliputi bengkak dan abses pada daerah suntikan karena jarum suntik tidak steril, nyeri dan pembengkakan kelenjar limfe (di daerah ketiak atau lipat paha), serta demam. Hal ini menimbulkan kekhawatiran dan ketakutan pada sebagian besar ibu sehingga menunda pemberian imunisasi (Achmadi, 2006).

Dampak dari keengganan ibu membawa bayinya ke posyandu untuk diimunisasi, adalah peningkatan kerentanan bayi terhadap berbagai penyakit infeksi. Bayi akan mudah terserang penyakit hepatitis B yang berpotensi menimbulkan kanker dan pengerasan hati (sirosis), penyakit polio yang mengakibatkan terjadinya kelumpuhan pada anggota gerak, tuberkulosis (TBC) yang dapat menimbulkan komplikasi berupa meningitis (radang selaput otak), diphtheria (penyakit akut saluran nafas bagian atas) yang dapat merusak jantung, ginjal dan sistem saraf, pertusis (whooping cough) atau lebih dikenal dengan istilah batuk rejan, tetanus, dan campak (measles) yang dapat menimbulkan komplikasi radang telinga tengah, pneumonia, diare serta radang otak (Achmadi, 2006).

Menurut hasil laporan imunisasi Provinsi Nanggroe Aceh Darussalam (NAD) sampai dengan bulan Desember tahun 2007, secara keseluruhan sebagian besar bayi yang menjadi sasaran telah mendapat imunisasi dasar meskipun masih ada bayi yang belum lengkap mendapat tindakan tersebut. Hal ini tampak dari pencapaian imunisasi campak secara kumulatif yang di bawah standar yaitu 76,43\% (DinKes NAD, 2008). Hasil studi pendahuluan di Desa Kajhu Kecamatan Baitussalam Aceh Besar, jumlah bayi 109 orang. Data laporan imunisasi sampai dengan bulan Agustus 2008, cakupan imunisasi dasar yang berhasil dicapai belum sesuai dengan yang diharapkan yaitu BCG (57,7\%), Polio 1 $(69,7 \%)$, Polio $2(61,4 \%)$, Polio $3(60,5 \%)$, Polio 4 (45,8\%), Campak (48,6\%) DPT-HB $1(56,8 \%)$, DPT-HB $2(64,2 \%)$, dan DPTHB $3(53,2 \%)$ (Puskesmas Kajhu, 2008). Hasil wawancara peneliti dengan ibu-ibu yang mempunyai anak bayi di desa Kajhu didapatkan bahwa, sebagian ibu ada yang membawa ulang untuk imunisasi, sebagian ada yang tidak membawa untuk diimunisasi ulang karena dilarang oleh suami dan takut anaknya sakit. Di samping itu peneliti juga belum mendapatkan gambaran secara pasti penyebab rendahnya cakupan imunisasi dasar di Desa Kajhu. Kesimpulan peneliti dari data tersebut bahwa cakupan imunisasi dasar pada bayi masih belum lengkap dan optimal.

\section{METODE}

Penelitian deskriptif korelatif dengan pendekatan cross sectional. Sampel diseleksi dengan tehnik simple random sampling 
sebanyak 52 orang dengan karakteristik: ibu yang memiliki anak balita usia 1 tahun; memiliki Kartu Menuju Sehat (KMS); menetap di Desa Kajhu Kecamatan Baitussalam Aceh Besar; bersedia menjadi responden; mampu membaca dan menulis.

Penelitian ini telah mengaplikasi prinsip etik (otonomy, beneficience, maleficience, dan justice) serta telah lulus uji etik dari komite etik Fakultas Ilmu Keperawatan Universitas Indonesia. Penelitian dilakukan di Desa Kajhu Kecamatan Baitussalam Aceh Besar sejak 26 Maret hingga 8 April 2009. Data dikumpulkan dengan menggunakan instrumen berupa kuesioner berbentuk angket. Hasil uji validitas terhadap instrumen yang ada didapatkan nilai korelasi $>0,632$ sehingga tidak ada butir pertanyaan yang direvisi atau dikeluarkan dari kuesioner. Kemudian dilakukan uji reliabilitas dan didapatkan hasil $>0,632$ sehingga kuesioner tersebut dinyatakan reliabel. Analisa bivariat hubungan antara motivasi ibu, dukungan keluarga, dan konseling dengan cakupan imunisasi dasar, dilakukan dengan uji statistik chi-square pada level of significance $(\mathrm{a})=0,05$.

\section{HASIL DAN PEMBAHASAN Univariat}

Tabel 1. Distribusi frekuensi menurut pendidikan ibu, motivasi ibu, dan dukungan keluarga di Desa Kajhu Kecamatan Baitussalam Aceh Besar tahun $2009(\mathrm{n}=52)$

\begin{tabular}{llcc}
\hline No & Distribusi & $\begin{array}{c}\text { Frekuensi } \\
(\mathrm{f})\end{array}$ & $\begin{array}{c}\text { Persentase } \\
(\%)\end{array}$ \\
\hline & Pendidikan & & \\
& ibu: & 11 & 21,10 \\
1. & Tinggi & 24 & 46,20 \\
2. & Menengah & 17 & 32,70 \\
3. & Dasar & & \\
\hline & $\quad$ Total & 52 & 100 \\
& Motivasi & & \\
& ibu: & & \\
1. & Tinggi & 28 & 53,80 \\
2. & Rendah & 24 & 46,20 \\
\hline \multicolumn{2}{r}{ Total } & 52 & 100 \\
\hline
\end{tabular}

\begin{tabular}{llcc}
\hline & $\begin{array}{l}\text { Dukungan } \\
\text { keluarga: }\end{array}$ & & \\
1. & Tinggi & 22 & 42,30 \\
2. & Rendah & 30 & 57,70 \\
\hline & Total & 52 & 100 \\
\hline
\end{tabular}

Dari tabel 1 diketahui distribusi pendidikan ibu sebagian besar adalah menengah sebanyak 24 orang $(46,20 \%)$, motivasi ibu sebagian besar adalah tinggi sebanyak 28 orang $(53,80 \%)$, dan dukungan keluarga sebagian besar adalah rendah sebanyak 30 orang $(57,70 \%)$.

Tabel 2. Distribusi frekuensi menurut konseling, dan cakupan imunisasi dasar di Desa Kajhu Kecamatan Baitussalam Aceh Besar tahun 2009 $(\mathrm{n}=52)$

\begin{tabular}{llcc}
\hline No & Distribusi & $\begin{array}{c}\text { Frekuensi } \\
\text { (f) }\end{array}$ & $\begin{array}{c}\text { Persentase } \\
(\%)\end{array}$ \\
\hline 1. & Konseling: & & \\
2. & Baik & 26 & 50,00 \\
& Tidak baik & 26 & 50,00 \\
& Total & 52 & 100 \\
& & & \\
& Cakupan & & \\
& imunisasi & & 55,80 \\
& dasar: & 29 & 44,20 \\
1. & Lengkap & 23 & \\
2. Tidak & & 100 \\
& lengkap & & \\
$\quad$ Total & 52 & \\
& & & \\
\hline
\end{tabular}

Dari tabel 2 diketahui distribusi konseling sama besar antara baik dan tidak baik dengan masing-masing sebanyak 26 orang (50\%), dan cakupan imunisasi dasar sebagian besar adalah lengkap sebanyak 29 orang $(55,80 \%)$.

\section{Bivariat}

Analisa bivariat hubungan antara motivasi ibu, dukungan keluarga, dan konseling dengan cakupan imunisasi dasar, dilakukan dengan uji statistik chi-square pada 
level of significance (a) $=0,05$ dengan tabel contigency $2 \times 2$ dan degree of fredoom (df) = 1 kecuali pada variabel pendidikan ibu yang menggunakan tabel contigency $3 \times 2$ dan degree of fredoom $(\mathrm{df})=2$. Hasil yang didapatkan sebagai berikut:

\section{Hubungan Pendidikan Ibu Dengan Cakupan Imunisasi Dasar Pada Bayi}

Dari tabel 3 diketahui pendidikan ibu dengan cakupan imunisasi dasar pada bayi tidak ada hubungan dengan $\mathrm{p}$ value $=0,115$.

\section{Hubungan Motivasi Ibu Dengan Cakupan Imunisasi Dasar Pada Bayi}

Dari tabel 4 diketahui hasil uji statistik dari sub variabel motivasi ibu dengan cakupan imunisasi dasar pada bayi didapatkan ada hubungan yang signifikan dengan $\mathrm{p}$ value $=$ 0,003 .

\section{Hubungan Dukungan Keluarga Dengan Cakupan Imunisasi Dasar Pada Bayi}

Dari tabel 5 diketahui hasil uji statistik dari sub variabel dukungan keluarga dengan cakupan imunisasi dasar pada bayi didapatkan ada hubungan yang sangat signifikan dengan $\mathrm{p}$ value $=0,000$.

\section{Hubungan Konseling Dengan Cakupan Imunisasi Dasar Pada Bayi}

Dari tabel 6 diketahui hasil uji statistik dari sub variabel konseling dengan cakupan imunisasi dasar pada bayi didapatkan tidak ada hubungan dengan $\mathrm{p}$ value $=0,402$.

Pada tabel 3 menunjukkan tidak ada hubungan antara pendidikan ibu dengan cakupan imunisasi dasar pada bayi dengan $p$ value $=0,115$. Bahwa perilaku seseorang untuk meningkatkan kesehatan menurut
Reinberg (2008) tidak terlepas dari pengaruh tingkat pendidikan yang berhasil diselesaikannya karena pendidikan akan meningkatkan pengetahuan akan manfaat pencegahan terhadap penyakit. Seseorang dengan tingkat pendidikan menengah akan mempunyai umur harapan hidup lebih tinggi dibandingkan dengan yang hanya lulus sekolah dasar. Demikian pula pada individu yang berhasil menyelesaikan pendidikan tinggi akan hidup lebih lama dibandingkan dengan pendidikan menengah.

Namun penelitian di Desa Kajhu bahwa pendidikan ibu yang tinggi pada sebagian masyarakat tidak berdampak pada kesamaan kedudukan ibu dalam pengambilan keputusan di dalam keluarga. Hal ini ditengarai keputusan dalam keluarga umumnya yang menyangkut dengan anak, harus mendapat persetujuan dari suami dan terkadang anggota keluarga lain seperti ibu mertua dan ibu kandung, sehingga bayi yang memiliki ibu dengan pendidikan tinggi belum dapat dipastikan akan mendapat imunisasi dasar lengkap. Hal ini sesuai dengan pendapat Karr yang dikutip Notoatmodjo (2005) bahwa keputusan seseorang untuk bertindak tidak hanya dipengaruhi oleh pendidikan namun sebagian besar terutama pada masyarakat yang masih memegang tradisi seperti Indonesia sangat dipengaruhi oleh otonomi atau kebebasan pribadi. Kurangnya kebebasan pribadi dalam memutuskan sesuatu pada kaum ibu terutama dialami ibu di daerah pedesaan dimana suami memegang peranan yang sangat besar dalam pengambilan keputusan. Seorang ibu tidak dapat memutuskan sendiri meskipun tindakan yang dilakukan untuk meningkatkan kesehatan dirinya atau anggota keluarga yang lain. Hasil yang sama mengenai tidak adanya hubungan yang bermakna antara tingkat pendidikan ibu dengan kelengkapan imunisasi bayi dikemukakan oleh Ismail dkk (2005). Penelitian dengan metode pengambilan sampel secara cluster di Provinsi Yogyakarta tersebut menemukan bahwa tidak ada 
hubungan yang bermakna antara tingkat pendidikan, pengetahuan tentang imunisasi, sumber informasi mengenai imunisasi, pekerjaan ibu, usia orang tua, dan jarak dengan puskesmas terdekat dengan imunisasi yang didapat bayi ( $\mathrm{p}$ value $>0,05$ ).

Tabel 3. Hubungan pendidikan ibu dengan cakupan imunisasi dasar pada bayi di Desa Kajhu Kecamatan Baitussalam Aceh Besar tahun 2009 ( $\mathrm{n}=52)$

\begin{tabular}{ccccccc}
\hline & & \multicolumn{2}{c}{ Cakupan imunisasi dasar } & & \\
No & $\begin{array}{c}\text { Pendidikan } \\
\text { ibu }\end{array}$ & \multicolumn{2}{c}{ pada bayi } & $\alpha$ & P value \\
\cline { 3 - 5 } & & Lengkap & $\begin{array}{c}\text { Tidak } \\
\text { lengkap }\end{array}$ & & & \\
\hline 1 & Tinggi & $7(6,1)$ & $4(4,9)$ & 11 & & \\
2 & Menengah & $16(13,4)$ & $8(10,6)$ & 24 & 0,05 & 0,115 \\
3 & Dasar & $6(9,5)$ & $11(7,5)$ & 17 & & \\
\hline & Total & 29 & 23 & 52 & & \\
\hline
\end{tabular}

Tabel 4. Hubungan motivasi ibu dengan cakupan imunisasi dasar pada bayi di desa Kajhu Kecamatan Baitussalam Aceh Besar tahun 2009 ( $\mathrm{n}=52)$

\begin{tabular}{|c|c|c|c|c|c|c|}
\hline \multirow{2}{*}{ No } & \multirow{2}{*}{$\begin{array}{l}\text { Motivasi } \\
\text { ibu }\end{array}$} & \multicolumn{2}{|c|}{$\begin{array}{c}\text { Cakupan imunisasi dasar } \\
\text { pada bayi }\end{array}$} & \multirow{2}{*}{ Total } & \multirow{2}{*}{$\alpha$} & \multirow{2}{*}{$\mathrm{P}$ value } \\
\hline & & Lengkap & $\begin{array}{c}\text { Tidak } \\
\text { lengkap }\end{array}$ & & & \\
\hline 1 & Tinggi & $21(15,6)$ & $7(12,4)$ & 28 & \multirow{3}{*}{0,05} & \multirow{3}{*}{0,003} \\
\hline 2 & Rendah & $8(13,4)$ & $16(10,6)$ & 24 & & \\
\hline & Total & 29 & 23 & 52 & & \\
\hline
\end{tabular}

Tabel 5. Hubungan dukungan keluarga dengan cakupan imunisasi dasar pada bayi di Desa Kajhu Kecamatan Baitussalam Aceh Besar tahun 2009 (n = 52)

\begin{tabular}{|c|c|c|c|c|c|c|}
\hline \multirow{2}{*}{ No } & \multirow{2}{*}{$\begin{array}{c}\text { Dukungan } \\
\text { keluarga }\end{array}$} & \multicolumn{2}{|c|}{$\begin{array}{c}\text { Cakupan imunisasi } \\
\text { dasar pada bayi }\end{array}$} & \multirow{2}{*}{ Total } & \multirow{2}{*}{$\alpha$} & \multirow{2}{*}{$\mathrm{P}$ value } \\
\hline & & Lengkap & $\begin{array}{c}\text { Tidak } \\
\text { lengkap }\end{array}$ & & & \\
\hline 1 & Tinggi & $21(12,3)$ & $1(9,7)$ & 22 & \multirow{3}{*}{0,05} & \multirow{3}{*}{0,000} \\
\hline 2 & Rendah & $8(16,7)$ & $22(13,3)$ & 30 & & \\
\hline & Total & 29 & 23 & 52 & & \\
\hline
\end{tabular}

Tabel 6. Hubungan konseling dengan cakupan imunisasi dasar pada bayi di Desa Kajhu Kecamatan Baitussalam Aceh Besar tahun 2009 ( $\mathrm{n}=52)$

\begin{tabular}{llccccc}
\hline & & \multicolumn{2}{c}{ Cakupan imunisasi } & & & \\
\cline { 3 - 4 } No & Konseling & Total & $\alpha$ & P value \\
\cline { 3 - 5 } 1 & Baik & $13(14,5)$ & $13(11,5)$ & 26 & & \\
\hline 2 & Tidak baik & $16(14,5)$ & $10(11,5)$ & 26 & 0,05 & 0,402 \\
\hline & Total & 29 & 23 & 52 & & \\
\hline
\end{tabular}


Pada tabel 4 menunjukkan ada hubungan yang signifikan antara motivasi ibu dengan cakupan imunisasi dasar pada bayi dengan $\mathrm{p}$ value $=0,003$. Hal ini sesuai dengan

pendapat Gray et. al. dalam Winardi (2001), bahwa motivasi merupakan sejumlah proses, yang bersifat internal atau eksternal bagi seorang individu yang menyebabkan timbulnya sikap antusiasme dan persistensi dalam hal melaksanakan kegiatan-kegiatan tertentu. Seorang ibu akan bersedia datang ke posyandu membawa anaknya untuk diimunisasi karena mempunyai motivasi tinggi yang didasari oleh berbagai faktor seperti keyakinan, nilai-nilai dan sebagainya (Notoatmodjo, 2005).

Hasil penelitian di Desa Kajhu, bahwa ibu yang memiliki motivasi tinggi merasa senang dengan pemberian imunisasi karena mengetahui bahwa tindakan yang diberikan tersebut akan mampu melindungi dari penyakit-penyakit berbahaya yang sering dialami bayi. Perasaan senang dan aman bila anak telah mendapat imunisasi mendorong ibu melengkapi lima imunisasi dasar yang wajib diterima bayi. Adanya hubungan motivasi ibu dengan cakupan lima imunisasi dasar pada bayi didukung oleh penelitian yang dilakukan oleh Mawar (2006). Penelitian terhadap bayi di wilayah kerja Puskesmas Kabuh Jombang menemukan bahwa cakupan imunisasi pada bayi yang menjadi sasaran terhadap lima imunisasi dasar meliputi 56\% untuk campak, 69\% untuk DPT1, 66\% untuk DPT3, 57\% untuk polio 4, 64\% untuk BCG dan $65 \%$ untuk HB3. Pencapaian ini menunjukkan cakupan imunisasi dasar masih di bawah target yang telah ditetapkan pemerintah sebesar $80,5 \%$ disebabkan motivasi yang rendah.

Pada tabel 5 menunjukkan ada hubungan yang signifikan antara dukungan keluarga dengan cakupan imunisasi dasar pada bayi dengan $\mathrm{p}$ value $=0,000$. Hal ini sesuai dengan teori bahwa dukungan keluarga merupakan salah satu faktor penting untuk terwujudnya perilaku sehat. Keluarga yang percaya akan keuntungan pemberian imunisasi bagi bayi dan institusi kesehatan akan mendorong anggota keluarga memanfatkan fasilitas kesehatan yang ada di lingkungan tempat tinggal seoptimal mungkin. Kepercayaan keluarga di daerah pedesaan biasanya tidak terlepas dari sosio budaya yang dianut masyarakat dimana bila prilaku yang dilakukan dianggap hal yang wajar maka akan lebih besar kemungkinan bayi mendapatkan imunisasi dasar lengkap (Notoatmodjo, 2005).

Hasil penelitian di Desa Kajhu memperlihatkan bahwa keluarga yang menyetujui dan mendukung keputusan untuk menghindarkan anak dari penyakit akan mendorong lengkapnya imunisasi dasar yang diterima bayi. Keadaan ini dikarenakan keluarga yang mendukung akan bersedia mengingatkan ibu akan jadwal imunisasi anak, membantu menjaga anak yang lain saat ibu membawa bayi diimunisasi, mengantarkan ibu ke tempat imunisasi, mengizinkan ibu terlepas dari urusan rumah tangga dan bersedia menjaga anak yang selesai diimunisasi bila mengalami kejadian ikutan pasca imunisasi sehingga tidak ada keadaan yang dapat menghalangi ibu atau menjadi alasan untuk tidak membawa anak diimunisasi. Hal ini sesuai dengan penelitian yang dilakukan oleh Yeni (2006) di Wilayah Puskesmas Candilama Kota Semarang bahwa target cakupan imunisasi dasar yang dapat dicapai sebesar $60 \%$. Penelitian dengan responden 86 orang tersebut menemukan bahwa faktor yang mempunyai hubungan dengan kelengkapan imunisasi dasar adalah pendidikan $(\mathrm{p}$ value $=0,003)$, pengetahuan ( $\mathrm{p}$ value $=0,000)$, sikap responden ( $\mathrm{p}$ value $=0,000)$, keutuhan responden $(\mathrm{p}$ value $=$ $0,000)$ dan dukungan keluarga ( $\mathrm{p}$ value $=$ 0,000).

Pada tabel 6 menunjukkan tidak ada hubungan antara konseling dengan cakupan imunisasi dasar pada bayi dengan $\mathrm{p}$ value $=$ 0,402 . Bahwa adanya informasi yang tepat mengenai seluk-beluk program kesehatan akan mendorong keinginan keluarga untuk menerima program tersebut. Salah satu 
program pemerintah yaitu pemberian imunsasi wajib akan lebih dapat diterima masyarakat bila penjelasan tentang tujuan imunisasi, manfaatnya bagi kesehatan anak, akibat yang dapat terjadi setelah imunisasi diberikan secara lengkap dan berkesinambungan serta selalu tersedia informasi bila masyarakat membutuhkannya (Notoatmodjo, 2005). Konseling yang baik mengenai imunisasi terutama mengenai Kejadian Ikutan Pasca Imunisasi (KIPI) pada ibu yang memiliki bayi telah terbukti memberikan ketenangan kepada ibu sehingga tidak takut membawa bayinya diimunisasi. Ibu yang telah mengerti bersedia menepati jadwal ulangan imunisasi sesuai dengan waktu yang telah diberitahukan petugas kesehatan dan akan mendorong ibu lain di sekitar tempat tinggalnya agar mengimunisasikan bayi (Endahwati, 2007).

Namun hasil penelitian di Desa Kajhu menunjukkan hal yang bertentangan dengan pendapat di atas bahwa tidak ada hubungan antara konseling dengan cakupan imunisasi dasar pada bayi. Keadaan ini dapat disebabkan oleh pemberian informasi yang diberikan petugas belum sepenuhnya dimengerti oleh masyarakat dan kemungkinan besar masih merupakan komunikasi satu arah dimana hanya petugas yang lebih banyak menginformasikan sesuatu dibandingkan masyakarat yang aktif bertanya. Hal lain yang dapat mendukung yaitu pemberian informasi belum melibatkan tokoh masyarakat setempat sehingga tidak ada faktor penguat yang dapat mendorong masyarakat melakukan tindakan yang sama.

Konseling dari petugas kesehatan dapat mempengaruhi keputusan orang tua untuk mengimunisasikan anaknya, seperti penelitian tentang perilaku ibu terhadap imunisasi yang dilakukan di PT Olagafood Industri, Tanjung Morawa, Medan. Responden penelitian yaitu wanita pekerja di pabrik mi instan Alhami dan istri karyawan pria yang tidak melakukan pekerjaan di luar rumah dengan syarat memiliki anak berusia di bawah lima tahun, dapat menunjukkan Kartu Menuju Sehat
(KMS) anak terkecilnya serta mampu menjawab seluruh pertanyaan secara lengkap. Hasil yang didapat yaitu sebagian sumber informasi ibu mengenai imunisasi diperoleh dari posyandu (42\%), masyarakat (16\%), klinik (13\%), bidan (12\%), puskesmas $(8 \%)$, dokter $(7 \%)$, dan media massa $(3 \%)$ namun $96 \%$ orang tua mengakui lebih menerima saran dokter sebelum memutuskan untuk mengimunisasikan anak mereka (Ali, 2003).

\section{KESIMPULAN DAN SARAN}

Berdasarkan pembahasan disimpulkan bahwa tidak ada hubungan faktor pendidikan dengan cakupan imunisasi dasar pada bayi dengan $\mathrm{p}$ value $=0,115$. Ada hubungan faktor motivasi ibu dengan cakupan imunisasi dasar pada bayi dengan $\mathrm{p}$ value $=0,003$. Ada hubungan dukungan keluarga dengan cakupan imunisasi dasar pada bayi dengan $\mathrm{p}$ value $=$ 0,000 . Tidak ada hubungan konseling dengan cakupan imunisasi dasar pada bayi dengan $\mathrm{p}$ value $=0,402$.

Saran yang dapat diberikan kepada dinas kesehatan melalui koordinasi dengan Puskesmas dapat menyesuaikan bentuk, isi dan cara penyuluhan tentang imunisasi dengan kondisi masyarakat yang menjadi tujuan dari penyampaian informasi sehingga dapat dipahami. Kepada Puskesmas lebih proaktif meningkatkan motivasi ibu untuk datang ke posyandu dengan menciptakan suasana yang menyenangkan terutama dengan lebih mengefektifkan meja ke 4 (meja imunisasi) dan mengidentifikasi hal-hal yang menjadi ketakutan ibu serta rintangan ibu untuk datang ke posyandu serta bersamasama melibatkan ibu mengatasi hal tersebut. Melakukan identifikasi keluarga yang kurang memberikan dukungan pada ibu untuk mengimunisasikan bayinya dan berusaha secara kontinyu memberikan informasi untuk mengarahkan cara berfikir keluarga agar mau menerima program-program pemerintah. Melakukan evaluasi terhadap konseling yang dilakukan selama ini terhadap masyarakat 
dengan meminta umpan balik cara penyampaian dan isi dari informasi kesehatan yang selama ini diberikan.

\section{DAFTAR PUSTAKA}

Ali, M. 2003. Pengetahuan, Sikap dan Perilaku Ibu Bekerja dan Ibu Tidak Bekerja Tentang Imunisasi. http:// library.usu. ac.id/download/fk/ anakmuhammad.pdf. Diakses pada 19 Agustus 2008.

Achmadi, U.F. 2006. Imunisasi Mengapa Perlu. Jakarta: Kompas Media Nusantara.

DepKes RI. 2007. Imunisasi: Modul Pelatihan Untuk Bidan dan Tenaga Kesehatan. Makalah yang dipresentasikan pada waktu pelatihan bidan dan tenaga kesehatan mengenai imunisasi. IDI. Aceh Timur.

Endahwati, L. 2007. Kampanye Campak Mulai Digelar Besok. http://www.dinfokom-jatim.go.id/. Diakses pada 28 Agustus 2008.

Irianto, K., Waluyo, K. 2004. Gizi dan Pola Hidup Sehat. Bandung: Yrama Widdya.

Ismail. 2008. Determinan Cakupan Imunisasi di Provinsi D.I. Yogyakarta. http: // www.damandiri.or.id/file/. Diakses pada 13 April 2009.

Mawar, R. 2006. Analisis Faktor Penyebab Pencapaian Imunisasi Bayi yang Rendah di Puskesmas Kabuh Jombang. http://adln.lib.unair.ac.id/. Diakses pada 13 April 2009.

Notoatmodjo, S. 2003. Ilmu Kesehatan Masyarakat. Jakarta: Rineka Cipta.

Reinberg, S. 2008. Life Expectancy Tied to Education. http://www.healthfinder. gov/ . Diakses pada 13 April 2009.

Sumniar, R.A. 2008. Pengaruh Tingkat Pendidikan Formal, Motivasi, Dukungan Keluarga dan Konseling Ibu Terhadap Imunisasi Dasar Lengkap pada Bayi di Desa Banjar Sengon Kecamatan Patrang Kabupaten Jember. http:// digilib. unej.ac.id/. Diakses pada 25 Pebruari 2009.
Yeni, R. 2006. Analisis Faktor-Faktor yang Berhubungan Dengan Praktik Ibu Dalam Pemberian Imunisasi Dasar di Wilayah Puskesmas Candilama Kota Semarang. http://www.mikm-undip. or.id/. Diakses pada 19 Agustus 2008. 